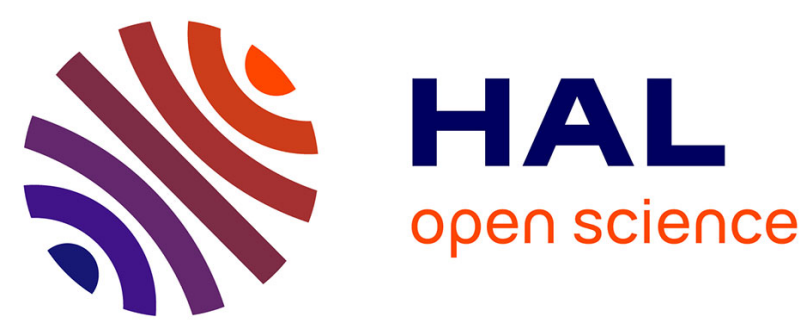

\title{
Effect of synthesis duration on the morphological and structural modification of the sea urchin-nanostructured $\gamma$-MnO2 and study of its electrochemical reactivity in alkaline medium
}

Lynda Benhaddad, Cyrille Bazin, Laid Makhloufi, Bouzid Messaoudi, Françoise Pillier, Kamal Rahmouni, Hisasi Takenouti

\section{To cite this version:}

Lynda Benhaddad, Cyrille Bazin, Laid Makhloufi, Bouzid Messaoudi, Françoise Pillier, et al.. Effect of synthesis duration on the morphological and structural modification of the sea urchin-nanostructured $\gamma-\mathrm{MnO} 2$ and study of its electrochemical reactivity in alkaline medium. Journal of Solid State Electrochemistry, 2014, pp.2111-2121. 10.1007/s10008-014-2459-2 . hal-01017797

\section{HAL Id: hal-01017797 https://hal.sorbonne-universite.fr/hal-01017797}

Submitted on 28 Aug 2014

HAL is a multi-disciplinary open access archive for the deposit and dissemination of scientific research documents, whether they are published or not. The documents may come from teaching and research institutions in France or abroad, or from public or private research centers.
L'archive ouverte pluridisciplinaire HAL, est destinée au dépôt et à la diffusion de documents scientifiques de niveau recherche, publiés ou non, émanant des établissements d'enseignement et de recherche français ou étrangers, des laboratoires publics ou privés. 


\title{
Effect of synthesis duration on the morphological and structural modification of the sea-urchin nanostructured $\gamma-\mathrm{MnO}_{2}$ and study of its electrochemical reactivity in alkaline medium
}

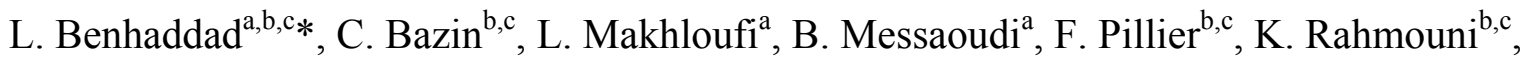 \\ H. Takenouti ${ }^{\text {b,c }}$ \\ ${ }^{a}$ Laboratoire d'électrochimie, corrosion et de valorisation énergétique (LECVE). Département de Génie des \\ Procédés. A. Mira University, Route de Targa Ouzemmour, 06000 Bejaia, Algeria. \\ ${ }^{b}$ CNRS, UPR 15, Laboratoire Interfaces et Systèmes Electrochimiques, (LISE, case courrier 133), 4 Place \\ Jussieu, F-75005, Paris, France \\ ${ }^{c}$ UPMC Univ. Paris VI, UPR 15, LISE, (case courrier 133), 4 Place Jussieu, F-75005, Paris, France
}

\begin{abstract}
Single crystalline nanorods and sea-urchin like morphology of the $\gamma-\mathrm{MnO}_{2}$ nanostructures were successfully synthesized by hydrothermal method at different synthesis durations. The as-synthesized products were characterized by the techniques X-Ray powder Diffraction (XRD), Field Emission Gun-Scanning Electron Microscope (FEG-SEM) coupled with Energy Dispersive X-ray elemental analysis (EDX), Transmission Electron Microscope (TEM), isotherms of $\mathrm{N}_{2}$ adsorption/desorption and BET-BJH models. The effect of synthesis duration on the morphology, porous structure, and crystallographic form of $\mathrm{MnO}_{2}$ powders was studied. The electrochemical reactivity of as prepared powders was investigated in $1 \mathrm{~mol} \mathrm{~L}^{-1}$ $\mathrm{KOH}$ by both cyclic voltammetry and impedance spectroscopy by using a micro-cavity electrode. The results show that the best electrochemical reactivity of the $\mathrm{MnO}_{2}$ powder obtained with synthesis duration of $24 \mathrm{~h}$.
\end{abstract}

Keywords: $\mathrm{MnO}_{2}$; Nanostructures; Hydrothermal synthesis; Micro-cavity electrode; impedance spectroscopy.

* Corresponding author, E-mail: benhaddad.lynda@gmail.com. Tel: +336 36256554 


\section{Introduction}

A great attention is directed nowadays towards nanostructured manganese dioxides because of their wide structural diversity combined with their unique physical and chemical properties and so for their many technological applications such as catalysis, batteries, supercapacitors and so on $[1-3]$.

Nanostructured manganese dioxide can be synthesized by electrochemical as well as chemical processes [4-8]. It was reported in the literature the synthesis of various nanostructures of manganese dioxide, such as nanotubes [9], nanowires, nanorods [10], nanoflowers [11], by thermal, sol-gel, soft chemical process, and hydrothermal methods. The effects of $\mathrm{pH}$, concentrations, temperature, reactants, counter-cations, and anions on the structure, crystallinity and morphology of the final products were extensively studied. In our previous papers [6-8], $\mathrm{MnO}_{2}$ powders were synthesized by hydrothermal method at different synthesizing temperature and different oxidizing agents. The products were presented as the sea-urchin like morphology, which was also obtained by reaction between $\mathrm{MnSO}_{4}$ and $\left(\mathrm{NH}_{4}\right)_{2} \mathrm{~S}_{2} \mathrm{O}_{8}$ at $100{ }^{\circ} \mathrm{C}$ for $20 \mathrm{~h} \mathrm{[12],} \mathrm{MnCl}_{2} \cdot 4 \mathrm{H}_{2} \mathrm{O} /\left(\mathrm{NH}_{4}\right)_{2} \mathrm{~S}_{2} \mathrm{O}_{8}$ at $90{ }^{\circ} \mathrm{C}$ for $12 \mathrm{~h}$ and $24 \mathrm{~h}$ [13], $\mathrm{KMnO}_{4} /$ concentrated $\mathrm{HNO}_{3}$ at $120{ }^{\circ} \mathrm{C}$ for $6 \mathrm{~h} \mathrm{[14].} \mathrm{We} \mathrm{have} \mathrm{remarked} \mathrm{that} \mathrm{the} \mathrm{morphology} \mathrm{of}$ $\mathrm{MnO}_{2}$ powder largely depend on the choice of reactants and experimental conditions. Actually, $\mathrm{MnO}_{2}$ nanowires in a powder form with a diameter of 10-50 nm were synthesized by both hydrothermal method [15] and soft chemical process [16].

As cited above [7], we have synthesized $\mathrm{MnO}_{2}$ powders at different temperatures $(60,90$ and $120{ }^{\circ} \mathrm{C}$ ) in order to study the influence of this parameter on the morphology, structure, and porosity of the obtained $\gamma-\mathrm{MnO}_{2}$ which presents the highest electrochemical reactivity compared to other crystalline varieties. The results showed that this parameter did not influence the morphology of powders, but influences their structures, porosities and their electrochemical reactivities. Indeed, the temperature of $90{ }^{\circ} \mathrm{C}$ give rise to the synthesis of $\gamma$ - 
$\mathrm{MnO}_{2}$ which is more electrochemically reactive than those synthesized at $60\left(\varepsilon-\mathrm{MnO}_{2}\right)$ and $120{ }^{\circ} \mathrm{C}\left(\beta-\mathrm{MnO}_{2}\right)$. Pang et al. [17] reported the hydrothermal synthesis of well-defined and fully developed $\alpha-\mathrm{MnO}_{2}$ nanorods at $80{ }^{\circ} \mathrm{C}$ for $24 \mathrm{~h}$. However, the increase of the temperature at $160{ }^{\circ} \mathrm{C}$ results in the formation of $\alpha-\mathrm{MnO}_{2}$ nanowires, in the first stage of reaction, which will be transformed to aggregates of microrods $\left(\beta-\mathrm{MnO}_{2}\right)$ with the increase of the synthesis time [18]. These results show that the temperature and synthesis duration play crucial role in accelerating the evolution of the nanostructures of $\mathrm{MnO}_{2}$. Other experimental conditions were also being studied in order to synthesize nanostructured $\mathrm{MnO}_{2}$ powder which presents the highest electrochemical reactivity $[19,20]$.

Manganese dioxides have many polymorphic forms, such as $\alpha$-, $\beta$-, $\gamma$-, $\delta$ - and $\lambda$ - which differ in the way in which the basic octahedral $\mathrm{MnO}_{6}$ units are linked together [21]. The nanostructured $\gamma-\mathrm{MnO}_{2}$ in powder form is an electrochemically active form, which is commonly used as a cathodic material in Leclanché and alkaline batteries.

The $\gamma-\mathrm{MnO}_{2}$ form is considered as a ramsdellite matrix with randomly distributed intergrown microdomains of pyrolusite, which are constructed with the basic building block of $\mathrm{MnO}_{6}$ units by edge and corner sharing, forming $(1 \times 1)$ and $(1 \times 2)$ tunnels, respectively [22]. Consequently, the $\gamma-\mathrm{MnO}_{2}$ displays the most complex structure because it contains defects (De Wolff disorder and microtwinning) [21]. As the physical and chemical properties of $\mathrm{MnO}_{2}$ powders depend strongly on the experimental conditions, great efforts were focused to optimize experimental conditions in order to synthesize a reactive $\gamma-\mathrm{MnO}_{2}$.

This paper focuses, firstly on the study of the effect of synthesis duration on the morphology, structure, crystallographic form, and the porosity of the $\mathrm{MnO}_{2}$ powders synthesized by hydrothermal method. The structure and morphology of the synthesized powders were characterized by the techniques of FEG-SEM, EDX, TEM and XRD. The methods of Brunauer-Emmett-Teller (BET) and Barret-Joyner-Halenda (BJH) were used to evaluate the 
specific surface area and the pore size distribution of the powders, respectively. Secondly, to compare the electrochemical reactivity of the $\mathrm{MnO}_{2}$ powders in $1 \mathrm{~mol} \mathrm{~L}^{-1} \mathrm{KOH}$ by means of cyclic voltammetry and electrochemical impedance spectroscopy with the helps of microcavity electrode.

\section{Experimental}

\subsection{Synthesis of $\mathrm{MnO}_{2}$ powders}

All the solutions were prepared using deionised water with double ion exchange columns. Manganese sulphate $\left(\mathrm{MnSO}_{4} \cdot \mathrm{H}_{2} \mathrm{O}\right)$ and ammonium persulphate $\left(\left(\mathrm{NH}_{4}\right)_{2} \mathrm{~S}_{2} \mathrm{O}_{8}\right)$ respectively, reactant and oxidizing agent, were purchased from Prolabo products and used as received.

The manganese dioxide $\left(\mathrm{MnO}_{2}\right)$ powders were synthesized by hydrothermal method as reported in our previous papers [6-8]. This method consisted of mixing 0.08 mol of $\mathrm{MnSO}_{4} \cdot \mathrm{H}_{2} \mathrm{O}$ and $0.08 \mathrm{~mol}$ of $\left(\mathrm{NH}_{4}\right)_{2} \mathrm{~S}_{2} \mathrm{O}_{8}$, in $150 \mathrm{~mL}$ of deionised water at room temperature. The mixture was stirred during 10 min to form a homogeneous pink solution. This solution was then heated at $90{ }^{\circ} \mathrm{C}$ for different synthesizing durations ( $6 \mathrm{~h}, 18 \mathrm{~h}, 24 \mathrm{~h}$ and 8 days). The products as precipitate thus obtained were filtered off, rinsed several times with deionised water, and finally dried at $60{ }^{\circ} \mathrm{C}$ for $24 \mathrm{~h}$.

The formation of $\mathrm{MnO}_{2}$ in a powder form occurs according to the following reaction:

$\mathrm{MnSO}_{4}+\left(\mathrm{NH}_{4}\right)_{2} \mathrm{~S}_{2} \mathrm{O}_{8}+2 \mathrm{H}_{2} \mathrm{O} \rightarrow \mathrm{MnO}_{2}+\left(\mathrm{NH}_{4}\right)_{2} \mathrm{SO}_{4}+2 \mathrm{H}_{2} \mathrm{SO}_{4}$

The electrochemical reactivity of $\mathrm{MnO}_{2}$ powders was investigated in $1 \mathrm{~mol} \mathrm{~L}^{-1} \mathrm{KOH}$ prepared with $\mathrm{KOH}$ (Merck product) and deionised water.

\subsection{Characterization of $\mathrm{MnO}_{2}$ powders}

The morphology and the elemental composition of the $\mathrm{MnO}_{2}$ powders were characterized by Field Emission Gun-Scanning Electron Microscope (FEG-SEM, Ultra 55 Zeiss) coupled with 
Energy Dispersive X-ray elemental analysis (EDX). In addition to these techniques, the X-ray powder diffraction (XRD) and the transmission electron microscopy (TEM) were also used.

TEM images were obtained with a JEOL 2000 FX microscope running at an accelerating voltage of $200 \mathrm{keV}$. Prior to analysis, the $\mathrm{MnO}_{2}$ powder was crushed in a mortar. A small amount was then added in pure ethanol and homogenized with ultrasonic bath. A drop of this mixture was placed on a copper grid covered with a carbon coating, and dried in air before analysis.

The results of the $\mathrm{N}_{2}$ adsorption/desorption isotherms, the pore size distribution, and BET surface area were determined by the Micromeritics Instrument. Prior to analysis, the powders were purged under vacuum at $80{ }^{\circ} \mathrm{C}$ to remove surface water, which would interfere with the instrument. The $\mathrm{N}_{2}$ adsorption/desorption isotherms were then collected at $77 \mathrm{~K}$. The pore size distribution and the surface areas of the samples were measured using the models BarrettJoyner-Halenda (BJH) and Brunauer-Emmett-Teller (BET) models, respectively.

\subsection{Experimental devices}

The electrochemical experiments were usually carried out in a three electrode cell: microcavity electrode as working electrode, calomel reference electrode in saturated $\mathrm{KCl}$ solution (SCE), and a platinum grid of large surface area as counter electrode. The micro-cavity electrode was made of platinum wire $(60 \mu \mathrm{m}$ in diameter) sealed in a glass tube $(8 \mathrm{~mm}$ in diameter) $[23,24]$. A small cylindrical cavity $(50 \mu \mathrm{m}$ in diameter and $25 \mu \mathrm{m}$ in depth) was formed by a laser ablation of the platinum wire. This cavity was filled with the $\mathrm{MnO}_{2}$ powder using the electrode as a pestle. This method constituted a marked advantage to study the $\mathrm{MnO}_{2}$ powder itself. First, the electrode was formed without any additive to give cohesion of powder. Second, the electrochemical process taking place at the substrate/electrolyte interface was negligible. Third, a thin powder layer allowed the minimization of the in-depth 
distribution of both potential and current, and finally, only a small amount of $\mathrm{MnO}_{2}$ is needed. The volume of the cavity used was $50 \cdot 10^{-9} \mathrm{~cm}^{3}[23,24]$. With the apparent specific gravity of $\mathrm{MnO}_{2}$ powder estimated at 2.2 , the mass necessary will be $110 \mathrm{ng}$ to perform experiments. The grinding of $\mathrm{MnO}_{2}$ into a fine powder before its introduction into the cavity permitted likely to homogenise $\mathrm{MnO}_{2}$ powder to be analysed. Consequently, this method also allowed the achievement of well-reproducible results.

Electrochemical measurements, including cyclic voltammetry $(\mathrm{CV})$ and electrochemical impedance spectroscopy (EIS) were carried out with a Potentiostat allowing determining low current and huge impedance (Gamry, Femstat FAS1). Both, the potentiostat and the electrochemical cell were set in a Faraday cage. The electrochemical impedance spectroscopy (EIS) measurements were carried out on the open circuit potential just before the beginning of each experiment with ac amplitude of $10 \mathrm{mV}$ in the frequency range from $10 \mathrm{kHz}$ to $1 \mathrm{mHz}$ by 10 points per decade. The impedance data were analyzed with in-house made software based on a simplex parameter regression.

\section{Results and discussion}

\subsection{Characterization of $\mathrm{MnO}_{2}$ powders}

The X-ray diffraction patterns of the powders obtained at different synthesis durations are presented at Figure 1. It can be seen that all patterns have similar peaks which are assigned to the values of (hkl) 120, 031, 131, 230, 300, 160, 401, 421, 062, and 450. All these peaks can be indexed to the crystallographic form $\gamma-\mathrm{MnO}_{2}$, which is in agreement with the reference (JCPDS Card no. 14-0644). However, others peaks are also detected and assigned to the values of (hkl) 200, 310, 411, 521, 541 and 332 as marked inside box.

These peaks can be indexed to the crystallographic form $\alpha-\mathrm{MnO}_{2}$ according to the reference (JCPDS Card no. 44-0141). It can be noted from Figure 1 (a) that the increase of synthesis 
duration of $6 \mathrm{~h}$ to $18 \mathrm{~h}$ leads to the increase of all peaks intensities. However, the pattern corresponding to $\mathrm{MnO}_{2}$ synthesized at $24 \mathrm{~h}$ shows also an increase in the intensity of the peaks of $\gamma-\mathrm{MnO}_{2}$, indicating a more crystalline product. However, the intensity of the peaks of $\alpha-\mathrm{MnO}_{2}$ decreases indicating the disappearance of this form from the structure of $\gamma-\mathrm{MnO}_{2}$, which allows us to consider this product as a pure $\gamma-\mathrm{MnO}_{2}$.

Figure 1 (b) shows that the increase of synthesis duration of $24 \mathrm{~h}$ to 8 days does not affects the intensity of the peaks of $\gamma-\mathrm{MnO}_{2}$ as shown by the superposition of the two patterns, but it can be well observed the increase of the intensity of the peaks of $\alpha-\mathrm{MnO}_{2}$, which reveals the reappearance of this crystallographic form and consequently the synthesized $\gamma-\mathrm{MnO}_{2}$ powder for 8 days is not pure. Then, no further characterizations were applied to this powder.

$<$ Figure 1 $>$

Fu et al. [25] reported that the synthesis of the pure crystalline $\gamma-\mathrm{MnO}_{2}$ depends strongly on the synthetic conditions such as the molar ratio (reactant/oxidant) which must be larger than $2.3\left(\mathrm{MnSO}_{4} / \mathrm{KMnO}_{4} \geq 2.3\right)$. Also, these authors [25] reported that the excess amount of $\mathrm{Mn}^{2+}$ in solution enhances two important phenomena: (a) crystallization of $\gamma-\mathrm{MnO}_{2}$ in short nanorods from poorly ordered nanoparticles; (b) formation of $\gamma-\mathrm{MnO}_{2}$ in hollow structures. Wang and $\mathrm{Li}$ [26] prepared $\beta-\mathrm{MnO}_{2}$ from a reaction between $\mathrm{MnSO}_{4}$ and $\left(\mathrm{NH}_{4}\right)_{2} \mathrm{~S}_{2} \mathrm{O}_{8}$; however, after the addition of $\left(\mathrm{NH}_{4}\right)_{2} \mathrm{SO}_{4}$ the $\beta-\mathrm{MnO}_{2}$ transform into $\alpha-\mathrm{MnO}_{2}$. It was reported that the cations (eg. $\mathrm{K}^{+}$and $\mathrm{NH}_{4}{ }^{+}$) are believed to be able to serve as inorganic templates for the formation of $\alpha-\mathrm{MnO}_{2}$ [27]. In our previous paper [7], we have remarked that the formation of $\gamma-\mathrm{MnO}_{2}$ occurred at $90{ }^{\circ} \mathrm{C}$ and it is stable in the course of time. The $\gamma-\mathrm{MnO}_{2}$ synthesized from a reaction between $\mathrm{MnSO}_{4}$ and $\left(\mathrm{NH}_{4}\right)_{2} \mathrm{~S}_{2} \mathrm{O}_{8}$ at $160{ }^{\circ} \mathrm{C}$ was rapidly transformed to $\beta-\mathrm{MnO}_{2}$ which is the most stable form at high temperatures compared to other varieties $[12,18]$. 
The FEG-SEM images of the $\mathrm{MnO}_{2}$ powders are presented at Figure 2. The morphology of the powders synthesized at $6 \mathrm{~h}, 18 \mathrm{~h}$ and $24 \mathrm{~h}$ is similar and is presented as the sea-urchin microparticles composed of many nanowires heaped together. It can be well observed that the diameter and the length of the nanowires increase with the increase of synthesis duration. It is well observed that the synthesis duration of $24 \mathrm{~h}$ leads to the formatin of sea-urchin microparticles covered with numerous crystalline and well-ordered nanowires. Also, it was reported in the literature, the hydrothermal synthesis of the sea-urchin particles of $\alpha-\mathrm{MnO}_{2}$ [28], and of $\beta-\mathrm{MnO}_{2}$ [29] covered by nanowires and nanorods, respectively. In our previous paper [6], the sea-urchin particles of $\gamma-\mathrm{MnO}_{2}$ covered by nanoneedles were synthesized from a reaction between $\mathrm{MnSO}_{4}$ and $\mathrm{Na}_{2} \mathrm{~S}_{2} \mathrm{O}_{8}$ at $90{ }^{\circ} \mathrm{C}$ for $24 \mathrm{~h}$.

However, the use of the oxidizing agent $\left(\mathrm{NH}_{4}\right)_{2} \mathrm{~S}_{2} \mathrm{O}_{8}$ leads to the synthesis of sea-urchin particles covered with nanowires as obtained in the present paper. Also, the increase of synthesis duration engenders an increase of the nanowires size and transformation of the seaurchin particles to nanorods which shows that this parameter influences the morphology and the crystallographic form of the $\mathrm{MnO}_{2}$ powders. In our previous paper [7] we remarked that the synthesis temperature equal or less than $120^{\circ} \mathrm{C}$ affects the crystallographic form of $\mathrm{MnO}_{2}$ powders but did not influences their morphologies. Zhou et al. [1] and Gao et al. [12] reported that the increase of temperature more than $120{ }^{\circ} \mathrm{C}$ induces significant changes in the morphology and the crystallographic form of $\mathrm{MnO}_{2}$.

\section{$<$ Figure 2 $>$}

Elemental analysis by EDX (Figure 3) confirms the presence of manganese and oxygen which compose the $\mathrm{MnO}_{2}$. On the all profiles, the presence of manganese is shown by two energy peaks appearing approximately at 6 and $6.5 \mathrm{keV}$ whereas that of oxygen is shown by one 
energy peak situated approximately at $0.5 \mathrm{keV}$. The presence of the sulphur coming from manganese sulphate is negligible.

$<$ Figure 3 $>$

The typical TEM images shown at Figure 4 indicate that the tiny wires of $\mathrm{MnO}_{2}$ powders, observed by SEM technique, depends on the synthesis duration. It can be observed that few nanowires are presented in the powders synthesized for $6 \mathrm{~h}$ and $18 \mathrm{~h}$ and that the number and the crystallinity of these nanowires increase with the increase of synthesis duration. The $\mathrm{MnO}_{2}$ synthesized for $24 \mathrm{~h}$ consisted of assembling of crystalline, straight wires with diameters in the range of $30-50 \mathrm{~nm}$ and lengths up to several hundred nanometers.

$<$ Figure $4>$

The $\mathrm{N}_{2}$ adsorption/desorption isotherms of $\mathrm{MnO}_{2}$ powders obtained with different synthesis duration are presented at Figure 5. These isotherms are of typical IV classification exhibiting the H3-type hysteresis loop which are characteristic of mesoporous materials. The three isotherms are characterized by a gradual increase of adsorbed gas, as a function of relative pressure, due to the condensation of the adsorbate in larger pores formed between particles. This phenomenon was observed with different particle size distributions of the same material $[30,31]$. As the desorption process is not reversible, these isotherms exhibit a substantial hysteresis loop in the $P / P_{0}$ range above 0.6 characteristics of mesoporous materials.

$<$ Figure $5>$

The pore size distribution of the three $\mathrm{MnO}_{2}$ powders determined by $\mathrm{BJH}$ method and the pore properties are presented at Figure 6 and table 1, respectively. The Figure 6 shows that $\mathrm{MnO}_{2}$ powders consist of the mesoporous distribution. The $\mathrm{MnO}_{2}$ powder synthesized for $6 \mathrm{~h}$ presents a pore size distribution between 2 and $50 \mathrm{~nm}$ with the quasi-total absence of 
micropores and macropores. The increase of synthesizing duration to attain $18 \mathrm{~h}$ leads to the enlargement of pores between 5 and $100 \mathrm{~nm}$ accompanied with the increase of pore volume.

However, two kinds of porosity can be observed from the pore size distribution corresponding to the $\mathrm{MnO}_{2}$ powder synthesized for $24 \mathrm{~h}$ : macropores with a maximum located between 70 and $100 \mathrm{~nm}$ and mesopores with a maximum between 20 and $30 \mathrm{~nm}$. As presented in table 1, the total pore volume of the powders increases with the increase of synthesis duration leading to a more porous powder.

$<$ Figure 6 $>$

The surface area of each powder was determined by the BET isotherm in conjunction with $\mathrm{N}_{2}$ adsorption data collected over the relative pressure range between 0.06 and 0.2 at $77 \mathrm{~K}$. In fact, at low relative pressures the isotherm underpredicts actual adsorption since the adsorption energies is higher than the expected value because of the surface inhomogeneity. In contrast, at high relative pressures, the BET isotherm overestimates adsorption because of limitations associated with liquefaction on the adsorbate [30]. The BET isotherm is expressed as follows:

$\frac{P}{V_{a}\left(P_{0}-P\right)}=\frac{1}{V_{m} C}+\frac{C-1}{V_{m} C} \frac{P}{P_{0}}$

Where, $V_{a}$ is the volume of gas adsorbed at $P / P_{0}\left(\mathrm{~cm}^{3} \mathrm{~g}^{-1}\right) ; V_{m}$ is the volume of gas that would occupy a monolayer $\left(\mathrm{cm}^{3} \mathrm{~g}^{-1}\right) ; C$ is a constant for the gas/solid pair; $P$ and $P_{0}$ are the equilibrium and the saturation pressures of adsorbate at the temperature of adsorption, respectively. The values of $V_{m}$ and $C$ can be evaluated from the plot $P /\left(V_{a}\left(P_{0}-P\right)\right)$ versus $P / P_{0}$ and consequently, the expanded surface area is calculated from the following expression:

$S=4.35 V_{m}$ 
It is noteworthy that the total surface area of a porous electrode is the sum of the surface area of all pores [31]. As recorded in table 1, the surface area increases with increasing synthesis duration due to the enlargement of pores and to the apparition of macropores. The surface area of $\mathrm{MnO}_{2}$ is generally comprised between 50 and $70 \mathrm{~m}^{2} \mathrm{~g}^{-1}$, which is the case of $\mathrm{MnO}_{2}$ powders synthesized for $6 \mathrm{~h}$ and $18 \mathrm{~h}$. However, the surface area of $\mathrm{MnO}_{2}$ synthesized for $24 \mathrm{~h}$ is therefore significantly larger than the value usually reported in the literature.

\subsection{Electrochemical reactivity of $\mathrm{MnO}_{2}$ powders}

The cyclic voltammetry and impedance spectroscopy techniques using a micro-cavity electrode were applied to characterize the electrochemical reactivity in $1 \mathrm{~mol} \mathrm{~L}^{-1} \mathrm{KOH}$ of $\mathrm{MnO}_{2}$ powders synthesized at different durations.

\subsubsection{Cyclic Voltammetry}

The micro-cavity electrode containing the $\mathrm{MnO}_{2}$ powder was transferred into $1 \mathrm{~mol} \mathrm{~L}^{-1} \mathrm{KOH}$ at ambient temperature without purging dissolved oxygen. Then, after one minute of stabilization time at the open circuit potential, the cyclic voltammetry measurements were carried out. The potential scan rate was $0.2 \mathrm{~V} \mathrm{~s}^{-1}$ and started from the open-circuit potential towards the negative direction up to $-0.7 \mathrm{~V}$ (vs. SCE), followed by the anodic scan up to $0.6 \mathrm{~V}$ (vs. SCE). Figure 7 presents cyclic voltammograms obtained at the first cycle. The results show that both anodic and cathodic peaks detected in the three cases are located at the same potential domain, thus they are ascribed to the same reactions. The comparison of these voltammograms shows the increase of cathodic and anodic peak intensities with the increase of synthesis duration of $6 \mathrm{~h}$ to $24 \mathrm{~h}$. Therefore, the $\mathrm{MnO}_{2}$ powder synthesized in $24 \mathrm{~h}$ has the highest electrochemical reactivity in $1 \mathrm{~mol} \mathrm{~L}^{-1} \mathrm{KOH}$.

$<$ Figure $7>$ 
From these voltammograms and during the cathodic scan, a current peak is observed clearly at around $-0.4 \mathrm{~V}$ (vs. SCE) which is attributed to the reduction of $\mathrm{MnO}_{2}$ to $\mathrm{MnOOH}$ by the diffusion of protons in the lattice of $\mathrm{MnO}_{2}$ according to the reaction (4).

$\mathrm{MnO}_{2}+\mathrm{H}^{+}+\mathrm{e}^{-} \rightarrow \mathrm{MnOOH}$

Kozawa and Yeager [32] have proposed a mechanism with two steps for the reduction of $\mathrm{MnO}_{2}$ from an alkaline medium. In the first step, an electron is inserted from the external circuit of the structure of $\mathrm{MnO}_{2}$ for the reduction of $\mathrm{Mn}^{4+}$ in $\mathrm{Mn}^{3+}$. To maintain the electroneutrality of the reaction, a water molecule, which is present at the interface $\mathrm{MnO}_{2} /$ electrolyte dissociates to give one proton $\mathrm{H}^{+}$, which will inserted in the structure of $\mathrm{MnO}_{2}$ while the ions $\mathrm{OH}^{-}$remains in solution. M. Minakshi [33] has studied the behaviour of $\mathrm{MnO}_{2}$ in an alkaline medium of $\mathrm{KOH}$ by using microscopic techniques. The results suggest that the electrode reaction of $\mathrm{MnO}_{2}$ in this electrolyte is the insertion of potassium $\left(\mathrm{K}^{+}\right)$, in addition to the usual protonation i.e. insertion of $\mathrm{H}^{+}$during the discharge process.

In aqueous solution, Toupin et al. [34] have proposed two possible mechanisms to explain this phenomenon. The first implicates the insertion of the protons $\left(\mathrm{H}^{+}\right.$, Eq. 4$)$ or the metallic cations $\left(\mathrm{K}^{+}\right.$, Eq. 5) into the matrix of $\mathrm{MnO}_{2}$ during the reduction followed by their expulsion during the oxidation reaction.

$\mathrm{MnO}_{2}+\mathrm{K}^{+}+\mathrm{e}^{-} \rightarrow \mathrm{MnOOK}$

The second mechanism presented by reaction (6) is expected to be predominant in the crystalline $\mathrm{MnO}_{2}$ and involves the insertion/expulsion of protons $\left(\mathrm{H}^{+}\right)$or cations $\left(\mathrm{M}^{+}\right)$into the material bulk:

$$
\left(\mathrm{MnO}_{2}\right)_{\text {surface }}+\mathrm{K}^{+}+\mathrm{e}^{-} \rightarrow\left(\mathrm{MnO}_{2}{ }^{-} \mathrm{K}^{+}\right)_{\text {surface }}
$$

The diffusion of protons and the facility with which they are inserted into the $\mathrm{MnO}_{2}$ matrix is widely admitted as the key electrochemical property during the discharge of this material and 
it is related in major part to the porosity of $\mathrm{MnO}_{2}$ [34-36] and/or to its hydration [37]. The presence of protons was identified by neutronic spectroscopy by Cachet et al. [38].

According to Tedjar and Guitton [37], the reduction of the varieties $\gamma_{-}, \varepsilon_{-}^{-}, \delta-\mathrm{MnO}_{2}$ is realized by the insertion of protons by jumping from a water molecule to another and that the more hydrated form has a higher electrochemical reactivity.

It was reported in the literature that the cathodic peak can be attributed to both reduction of $\mathrm{MnO}_{2}$ and reduction of dissolved oxygen since they have a potential very close in alkaline medium $[39,40]$. The mechanism of the oxygen reduction was proposed to be a coupled reaction involving the redox pair $\mathrm{MnO}_{2} / \mathrm{MnOOH}$ [41].

During the anodic scan, a current peak was observed on the three voltammograms at a potential around $0.3 \mathrm{~V}$ (vs. SCE). This peak corresponds to the oxidation of $\mathrm{MnOOH}$ formed previously to $\mathrm{MnO}_{2}$ according to the reverse reaction of (4 or 5). The intensity of this peak is better in the case of $\mathrm{MnO}_{2}$ synthesized for $24 \mathrm{~h}$.

The cathodic charge used for the reduction of $\mathrm{MnO}_{2}(\mathrm{j}<0)$ as function of the scan's number for the $\mathrm{MnO}_{2}$ powders synthesized at different durations is presented at Figure 8. It can be well observed that the cathodic charge increases with the increase of the synthesis duration and the scan's number increase which means that the powder synthesized for $24 \mathrm{~h}$ is the most reactive form in the test medium compared to other powders.

$<$ Figure $8>$ 
The cathodic charge of the $\mathrm{MnO}_{2}$ powder synthesized in $24 \mathrm{~h}$ as function of scan's number of different scan rates is presented at Figure 9. As observed, the increase of the scan rate engenders a decrease of the cathodic charge which corresponds to the decrease of the amount of charges inserted in the structure of $\mathrm{MnO}_{2}$. From this, it can be concluded that the insertion of protons into the structure of $\mathrm{MnO}_{2}$ is slow which requires a longer time. It was also observed that the cathodic charge increases with the increase of scan's number at a scan rate of $0.2 \mathrm{~V} \cdot \mathrm{s}^{-1}$ while it is stable in the other cases.

$<$ Figure 9 $>$

The micro-cavity electrode containing the $\mathrm{MnO}_{2}$ powder was transferred into $1 \mathrm{~mol} \mathrm{~L}^{-1} \mathrm{KOH}$ and after different stabilization time at the open circuit potential $(30 \mathrm{~s}, 60 \mathrm{~s}, 10 \mathrm{~min}$ and 30 $\mathrm{min}$ ), the cyclic voltammetry measurements were carried out. The potential scan rate was 0.2 $\mathrm{V} \mathrm{s}^{-1}$ and the scan started from the open-circuit potential towards the negative direction up to $-0.7 \mathrm{~V}$ (vs. SCE), followed by the anodic scan up to $0.6 \mathrm{~V}$ (vs. SCE).

The cathodic charge as function of the scan's number for different stabilization times is determined and the results are presented at Figure 10. From this figure, it can be well observed that the increase of stabilization time from $30 \mathrm{sec}$ to $60 \mathrm{sec}$ engenders an increase of the cathodic charge due to the insertion of charges into the structure of $\mathrm{MnO}_{2}$ during the stabilization time. However, the increase of stabilization time to $10 \mathrm{~min}$ and $30 \mathrm{~min}$ causes the decrease of the cathodic charge which is due probably to the occupation of all active sites of the $\mathrm{MnO}_{2}$ powder by charges or to its deterioration in the test medium. It can be observed that the cathodic charge of the $\mathrm{MnO}_{2}$ powder still constant for stabilization times equal or greater than 10 min which reveals that the amount of charges inserted into the structure of $\mathrm{MnO}_{2}$ is limited.

$<$ Figure 10 $>$ 
As reported above, the $\mathrm{MnO}_{2}$ powder synthesized for $24 \mathrm{~h}$ presents the highest electrochemical reactivity in $1 \mathrm{~mol} \mathrm{~L}^{-1} \mathrm{KOH}$ compared with other powders. This is due probably to its porosity, its nanostructured form, or to its crystallographic form $\gamma-\mathrm{MnO}_{2}$ recognized as the most reactive form. It is difficult to determine the major factor which is responsible for the high reactivity of this powder in the test medium, but, we think that each parameter can contribute. A detailed discussion is presented in section 3.3.

\subsubsection{Electrochemical Impedance Spectroscopy}

Nyquist impedance spectra presented at Figure 11 were obtained in $1 \mathrm{~mol} \mathrm{~L}^{-1} \mathrm{KOH}$ in the frequency range from $10 \mathrm{kHz}$ to $1 \mathrm{mHz}$ after ageing with cyclic voltammetry for $10 \mathrm{scans}$ at $0.2 \mathrm{~V} \mathrm{~s}^{-1}$. The EIS diagrams exhibit though badly separated two capacitive loops in high and medium frequency range and a linear branch in the lower frequencies corresponding to the diffusion of protons into the lattice of $\mathrm{MnO}_{2}$. The slope of this linear branch is different for the three powders.

$<$ Figure 11 $>$

The recorded data may be represented by an equivalent electrical circuit named $2 \mathrm{RC}-\mathrm{C}$ shown at Figure 12. In this circuit, $R_{\mathrm{e}}$ represents the electrolyte resistance between the reference and the working electrode; $R_{\mathrm{t}}$ and $C_{\mathrm{d}}$ are allocated, respectively, to the charge transfer resistance in parallel with the double layer capacitance; $R_{\mathrm{F}}$ and $C_{\mathrm{F}}$ stand for faradaic impedance associated with the reduction of dissolved oxygen; $C_{\mathrm{ac}}$ characterizes the capacitance corresponding to charge storage in the chemical form, i.e. corresponding to a proton $\left(\mathrm{H}^{+}\right)$ insertion/expulsion process. This capacitance is therefore the determining parameter in the use of $\mathrm{MnO}_{2}$ as battery material; $n_{\mathrm{d}}, n_{\mathrm{F}}, n_{\mathrm{ac}}$ are allowed reproducing a depressed feature of impedance diagram in Nyquist plane (Cole-Cole coefficient), and they will be valued between 0 and 1. 
To compare the electrochemical reactivity of $\mathrm{MnO}_{2}$ powders in the test medium, it is appropriate to evaluate the values of the capacitance $C_{\mathrm{ac}}$ by using a simplex parameter regression. As reported above, the diagrams are presented as two badly separated capacitive loops and a linear branch. It was considered that the couple $R_{\mathrm{t}} / C_{\mathrm{d}}$ exhibits the highest frequency range (centered at about $315 \mathrm{~Hz}$ ) and the couple $R_{\mathrm{F}} / C_{\mathrm{F}}$ exhibit the medium frequency range (centered at about $0.1 \mathrm{~Hz}$ ). The capacitance $C_{\mathrm{ac}}$ expresses itself in the lowest frequency range.

The parameter regression shows that the best value of the capacitance $C_{\mathrm{ac}}$ is equal to $7.1 \mu \mathrm{F}$ corresponding to the $\mathrm{MnO}_{2}$ powder synthesized for $24 \mathrm{~h}$ showing its high electrochemical reactivity in the test medium compared with other powders, which confirms cyclic voltammetry results. The regression results show also a decrease of charge transfer and faradaic resistances $\left(R_{\mathrm{F}}\right)$, associated with the reduction of dissolved oxygen, with the increase of synthesis duration. As reported above, the mechanism of the oxygen reduction involves the redox reaction between $\mathrm{MnO}_{2}$ and $\mathrm{MnOOH}$ initiated by the diffusion of protons. Therefore, the decrease of faradaic resistance reveals the ease in which protons are inserted into the structure of $\mathrm{MnO}_{2}$ powder synthesized for $24 \mathrm{~h}$ thus leading to the reduction of $\mathrm{MnO}_{2}$ into $\mathrm{MnOOH}$ and consequently in the reduction of dissolved oxygen. Mao et al. [42] showed that $\mathrm{MnOOH}$ exhibits the highest catalytic activity for the electrochemical reduction of dissolved oxygen among the various varieties of manganese oxides.

The effect of powder ageing was examined by submitting the $\gamma-\mathrm{MnO}_{2}$ powder synthesized at $90{ }^{\circ} \mathrm{C}$ for $24 \mathrm{~h}$ to cyclic voltammetry in $1 \mathrm{~mol} \mathrm{~L}^{-1} \mathrm{KOH}$ for 10 scans at $0.01 \mathrm{~V} \mathrm{~s}^{-1}$ followed by its characterization by EIS measurements in the frequency range from $10 \mathrm{kHz}$ to $10 \mathrm{mHz}$. The obtained diagram was compared with that recorded before potential cycling. The diagrams presented at Figure 13 exhibit two capacitive loops and a capacitive linear branch at low 
frequencies. It was observed that the ageing of $\mathrm{MnO}_{2}$ powder in the test medium leads to the enlargement of the Nyquist diagram indicating an increase of charge transfer and the faradaic resistances in parallel with a decrease of the capacitance $C_{\mathrm{ac}}$. Indeed, the ageing of $\mathrm{MnO}_{2}$ powder in the medium leads to the insertion of large amount of charges into its structure. The free active sites will be occupied by charges which engenders the increase of the resistances of faradaic and charge transfer. So, it can be concluded that the ageing of $\mathrm{MnO}_{2}$ powder in the test medium engenders the decrease of its active sites and/or to its mechanical failure during cycling which provoke to the decrease of its capacitance $C_{\mathrm{ac}}$.

$<$ Figure 13 $>$

\subsection{Discussion}

The defects have been considered as one of the most crucial factors to determine the electrochemical performance of $\gamma-\mathrm{MnO}_{2}$ materials, and have been studied intensively [43-45]. According to Chabre and Pannetier [21], two types of defects are present. The first one is De Wolff disorder, which is formed from the insertion of pyrolusite structural units into ramsdellite matrix, relating to the amount of pyrolusite units. The second type is called microtwinning defects, which are generated by twinning in (021) and (061) planes within the ramsdellite blocks. According to these authors, the Microtwinning defects enhances the electrochemical reactivity of $\gamma-\mathrm{MnO}_{2}$ materials whereas De Wolff disorder defects lowers them [21]. However, Balachandran et al. [36] reported that the introduction of microtwinning defects as well as De Wolff disorder can have a large adverse effect on the proton diffusion inside $\mathrm{MnO}_{2}$. The results showed that the kinetics of $\gamma-\mathrm{MnO}_{2}$ reduction is slows down towards the end of discharge attributed to the decrease of proton diffusion which is contradicting with the model of Chabre and Pannetier. 
Different mechanisms of the $\mathrm{MnO}_{2}$ reduction in an alkaline medium were proposed in the literature [43-50]. Burns has suggested that $\gamma-\mathrm{MnO}_{2}$ used as cathodic material in batteries might contain lattice defects such as "stacking faults, dislocations, chain defects, etc.". He also suggested that such defects might account for the high water content and the high electrochemical reactivity of $\gamma-\mathrm{MnO}_{2}$ [46]. In 1984, P. Ruetschi has proposed a cationvacancy model for $\gamma$ - or $\varepsilon-\mathrm{MnO}_{2}$ [45]. In his report, Ruetschi explained that the reason for which $\gamma$ - and $\varepsilon-\mathrm{MnO}_{2}$ are more reactive than $\beta-\mathrm{MnO}_{2}$ is due to the presence of $\mathrm{Mn}$ vacancies and corresponding water content thus providing an initial starting concentration of protons for the transfer process. In contrast, $\beta-\mathrm{MnO}_{2}$ did not contains almost no vacancies and thus very little structural water. This model was confirmed later by Petit et al [47], Fillaux et al. [48], and Balachandran et al. [49], but contradicted by Tedjar and Guitton [37] and Ananth et al. $[50]$.

As reported previously, Toupin et al. [34] proposed two possible mechanisms to explain the phenomenon of $\mathrm{MnO}_{2}$ reduction from an aqueous solution. The first implicates the insertion of protons $\left(\mathrm{H}^{+}\right.$, Eq. 4) and metallic cations $\left(\mathrm{K}^{+}\right.$, Eq. 5) into the matrix of $\mathrm{MnO}_{2}$. In an alkaline medium, Amarilla et al. [51] reported that the electrochemical behaviour of $\gamma-\mathrm{MnO}_{2}$ depends strongly on the $\mathrm{KOH}$ concentration. During the discharge process of the first cycle, one step reduction in $1 \mathrm{~mol} \mathrm{~L}^{-1} \mathrm{KOH}$ and two step reduction in $[\mathrm{KOH}] \geq 3 \mathrm{~mol} \mathrm{~L}^{-1}$ were observed. The first reduction step assigned to the insertion process of $\mathrm{H}^{+} / \mathrm{e}^{-}$increases when the $\mathrm{KOH}$ concentration decreases which means that $\gamma-\mathrm{MnO}_{2}$ loses its electrochemical reactivity when the concentration of electrolyte increases. Minakshi et al. [33] studied the effect of $\mathrm{K}^{+}$ions on the reduction mechanism of $\mathrm{MnO}_{2}$ from an alkaline medium of $\mathrm{KOH} 5 \mathrm{~mol} \mathrm{~L}^{-1}$. The results show the insertion/expulsion of $\mathrm{K}^{+}$on the surface of $\mathrm{MnO}_{2}$, which reduces the electron transfer and therefore a decrease of the electrochemical reactivity. Zhang reported that EMD and CMD display the same XRD patterns, showed a different electrochemical reactivity [52]. 
Therefore, in such cases, the electrochemical behaviour of these $\gamma-\mathrm{MnO}_{2}$ powders cannot be properly explained based on the model of Chabre and Pannetier. Zhang considered that this model is extremely useful in dealing with $\gamma-\mathrm{MnO}_{2}$ materials with a different XRD patterns. For those materials showing little difference in XRD patterns, it is necessary to take into account other factors like differences in physical or chemical properties [52]. Also, Zhang suggested that high porosity and surface area are probably related to the amount of defects presented in the structure of $\mathrm{MnO}_{2}$ which facilitates the protons diffusion and electron transfer during the $\mathrm{MnO}_{2}$ reduction, and therefore outcome high electrochemical reactivity [52]. Indeed, several research projects reported that more the surface area is larger better is the electrochemical behaviour of $\mathrm{MnO}_{2}$ [53-55]. Reddy and Reddy [56] remarked that the specific capacitance of $\mathrm{MnO}_{2}$ depends on the distribution of pore size rather than BET surface area.

However, it was reported in the literature [52] that $\gamma-\mathrm{MnO}_{2}$ materials of low surface area and high density are more active than light or puffy materials of low density and high surface area probably because in a dense and compact form the electron conduction is facilitated, which was also reported in our previous paper where $\gamma-\mathrm{MnO}_{2}$ synthesized by $\mathrm{Na}_{2} \mathrm{~S}_{2} \mathrm{O}_{8}\left(40 \mathrm{~m}^{2} \mathrm{~g}^{-1}\right)$ was more reactive in $1 \mathrm{~mol} \mathrm{~L}^{-1} \mathrm{KOH}$ than $\gamma-\mathrm{MnO}_{2}$ synthesized by $\left(\mathrm{NH}_{4}\right)_{2} \mathrm{~S}_{2} \mathrm{O}_{8}\left(90.8 \mathrm{~m}^{2} \mathrm{~g}^{-1}\right)$ [6].

Up till now, much works attempts to correlate the physical, chemical and structural properties of $\gamma-\mathrm{MnO}_{2}$ materials (EMD, CMD, and NMD) with their electrochemical reactivity in batteries but it is still unsolved and remains a key research challenge for researchers in raison of the complexity of $\gamma-\mathrm{MnO}_{2}$ structure.

\section{Conclusions}

Two different nanostructures of $\gamma-\mathrm{MnO}_{2}$ were successfully synthesized by hydrothermal method at different synthesis durations. Indeed, sea urchin particles covered by nanowires 
were obtained in the first stage of synthesis which were transformed to nanorods with the increase of synthesis duration. The structural characterization of $\gamma-\mathrm{MnO}_{2}$ powders shows that the synthesis duration affects the porous structure and the crystallographic form of powders. The study of the electrochemical reactivity of these powders in $1 \mathrm{~mol} \mathrm{~L}^{-1} \mathrm{KOH}$ was performed by using micro-cavity electrode. Best results were obtained in the case of $\gamma-\mathrm{MnO}_{2}$ synthesized for $24 \mathrm{~h}$ compared with other synthesized powders.

\section{Acknowledgements.}

The present work was carried out in the frame of French - Algerian cooperation project CMEP- PHC Tassili Nº 06 MDU 686. The authors thank efficient assistance of all technicians of the laboratory LISE for the characterization of powders.

\section{REFERENCES AND NOTES}

1. Zhou L, Zhang J, He J, Hu Y, Tian H (2011) Mater Res Bull 46:1714-1722

2. Cui HJ, Huang HZ, Fu ML, Yuan BL, Pearl W (2011) Catal Comm 12:1339-1343.

3. Jou JH, Shi JW, Liu F, Fu ML (2011) J Mater Chem 21:18527-18529.

4.Cherchour N, Deslouis C, Messaoudi B, Pailleret A (2011) Electrochim Acta 56:9746-9755

5. Messaoudi B, Joiret S, Keddam M, Takenouti H (2001) Electrochim Acta 46:2487-2498

6. Benhaddad L, Makhloufi L, Messaoudi B, Rahmouni K, Takenouti H (2011) J Mater Sci Technol 27:585-593

7. Benhaddad L, Makhloufi L, Messaoudi B, Rahmouni K, Takenouti H (2009) ACS Appl Mater Interfaces 1 (2):424-432

8. Benhaddad L, Makhloufi L, Messaoudi B, Rahmouni K, Takenouti H (2007) Matériaux et Techniques 95:405-410

9. Xiao W, Xia H, Fuh JYH, Lu L (2009) J Power Sources 193:935-938

10. Wang X and Li Y (2003) Chem. Eur J 9 (1):300-306 
11. Li Y, Wang J, Zhang Y, Banis MN, Liu J, Geng D, Li R, Sun X (2012) J Colloid Interface Sci 369:123-128

12. Gao T, Fjellvåg H, Norby P (2009) Nanotechnology 20(5):055610-055616

13. Zhou M, Zhang X, Wang L, Wei J, Wang L, Zhu K, Feng B (2011) Mater Chem Phys 130 (3):1191-1194

14. Tang N, Tian X, Yang C, Pi Z (2009) Mater Res Bull 44:2062-2067

15. Liu Y, Zhang M, Zhang J, Qian Y (2006) J Solid State Chem 179:1757-1761

16. Wei M, Konishi Y, Zhou H, Sugihara H, Arakawa H (2005) Nanotechnology 16:245

17. Pang SC, Chin SF, Ling CY (2012) J Nanomaterials Article ID 2012:607870

18. Guan H, Chen G, Zhang S, Wang Y (2010) Mater Chem Phys 124:639-645

19. Wang HE, Qian D, Lu Z, Li Y, Cheng R, Zhang W (2007) J. Cryst. Growth, doi: 10./016/j.jcrysgro.2007.01.034

20. Subramanian V, Zhu H, Vajtai R, Ajayan PM, Wei B (2005) J Phys Chem B 109:2020720214

21. Chabre Y and Pannetier J (1995) Prog Solid State Chem 23:1-130

22. De Wollf PM (1959) Acta Crystallogr 12:341-345

23. Vivier V, Cachet-Vivier C, Wu BL, Cha CS, Nedelec JY, Yu LT (1999) Electrochem Solid-State Lett 2 (8):385-387

24. Vivier V, Cachet-Vivier C, Cha CS, Nedelec JY, Yu LT (2000) Electrochem Commun $2: 180-185$

25. Fu X, Feng J, Wang H, Ng KM (2009) Nanotechnology 20:375601

26. Wang X and Li YD (2002) J Am Chem Soc 124:2880-2881

27. Liu J, Makwana V, Cai J, Sui SL, Aindow M (2003) J Phys Chem B 107:9185-9194

28. Zhang Z and Mu J (2007) Solid State Commun 141:427-430

29. Ghodbane O, Pascal JL, Favier F (2009) ACS Appl Mater Interfaces 1(5):1130-1139 
30. Arnott JB, Williams RP, Pandolfo AG, Donne SW (2007) J Power Sources 165 (2):581590

31. Qu D. (2003) Electrochim Acta 48 (12):1675-1684

32. Kozawa H, Heager JF (1965) J Electrochem Soc 112:959-963

33. Minakshi M (2008) J Electroanal Chem 616:99-106.

34. Toupin M, Brousse T, Bélanger D (2004) Chem Mater 16:3184-3190

35. Hong Z, Zhenhai C, Xi X (1989) J Electrochem Soc 136 (10):2771-2774

36. Balachandran D, Morgan D, Ceder G (2002) J Solid State Chem 166:91-103

37. Tedjar F and Guitton J (1985) Surface Technology 26 (2):107-115

38. Cachet C, Belushkin A, Natkaniec I, Lecerf A, Fillaux F, Yu LT (1995) Physica B 213$214: 827-829$

39. Cao YL, Yang HX, Ai XP, Xiao LF (2003) J Electroanal Chem 557:127-134

40. Roche I and Scott K (2010) J Electroanal Chem 638:280-286

41. Brenet JP (1979) J Power Sources 4:183-190

42. Mao L, Sotomura T, Nakatsu K, Nobuharu K, Zhang D, Ohsaka T (2002) J Electrochem Soc 149 (4):A504-A507

43. Ruetschi P and Giovanoli R (1988) J Electrochem Soc 135 (11):2663-2669

44. Parida KM, Kanungo SB, Sant BR (1981) Electrochim Acta 26:435-443

45. Ruetschi P (1984) J Electrochem Soc 131 (12):2737-2744

46. Burns RG (1984) Battery Material Symposium. In A. Kozawa.and M. Nagayama (Ed), Vol I. Brussels 1983, published by BMRA, Cleveland, OH, pp 197

47. Petit F, Lenglet M, Arsène (1993) J Mater Res Bull 28:1093-1100

48. Fillaux F, Cachet CH, Ouboumour H, Tomkinson J, Lévy-Clément C, Yu LT (1993) J Electrochem Soc 140 (3):585-591 
49. Balachandran D, Morgan D, Ceder G, Van de Walle A (2003) J Solid-State Chem $173: 462-475$

50. Ananth MV, Pethkar S, Dakshinamurthi K (1998) J Power Sources 75 (2):278-282

51. Amarilla JM, Tedjar F, Poinsignon C (1994) Electrochim Acta 39 (15):2321-2331

52. Zhang Q (2001) I. Syntheses of Manganese oxides by using microwave heating and conventional heating, II. Syntheses of nanosize materials. Thesis PHD Connecticut University 53. Lee HY, Kim SW. Lee HY (2001) Electrochem Solid-State Lett 4 (3):A19-A22

54. Devaraj S and Munichandraiah N (2005) Electrochem Solid-State Lett 8(7):A373-A377

55. Devaraj S and Munichandraiah N (2007) J Electrochem Soc 154 (10):A901-A909

56. Reddy RN and Reddy RG (2003) J Power Sources 124:330-337 
Figure 1
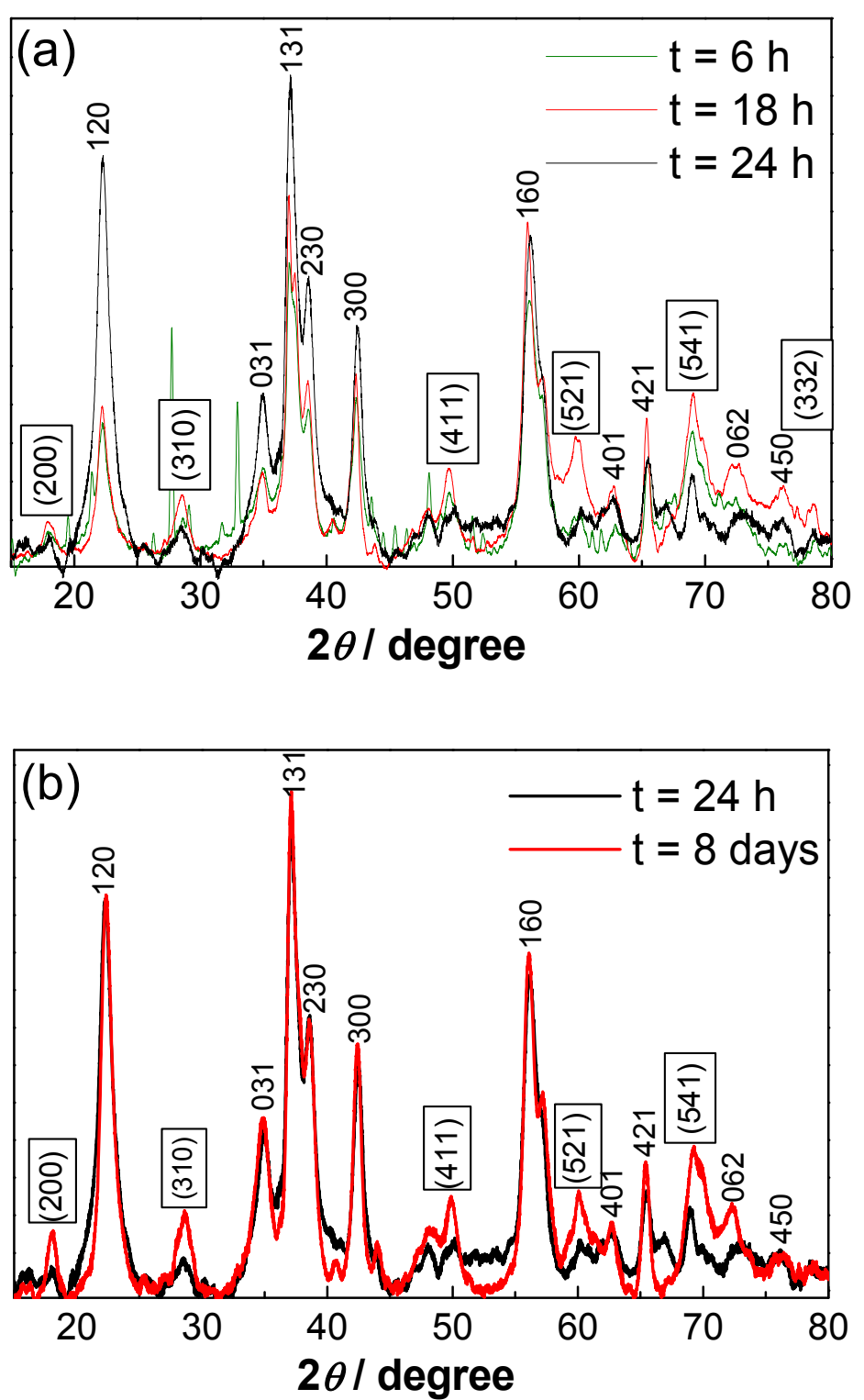
Figure 2.
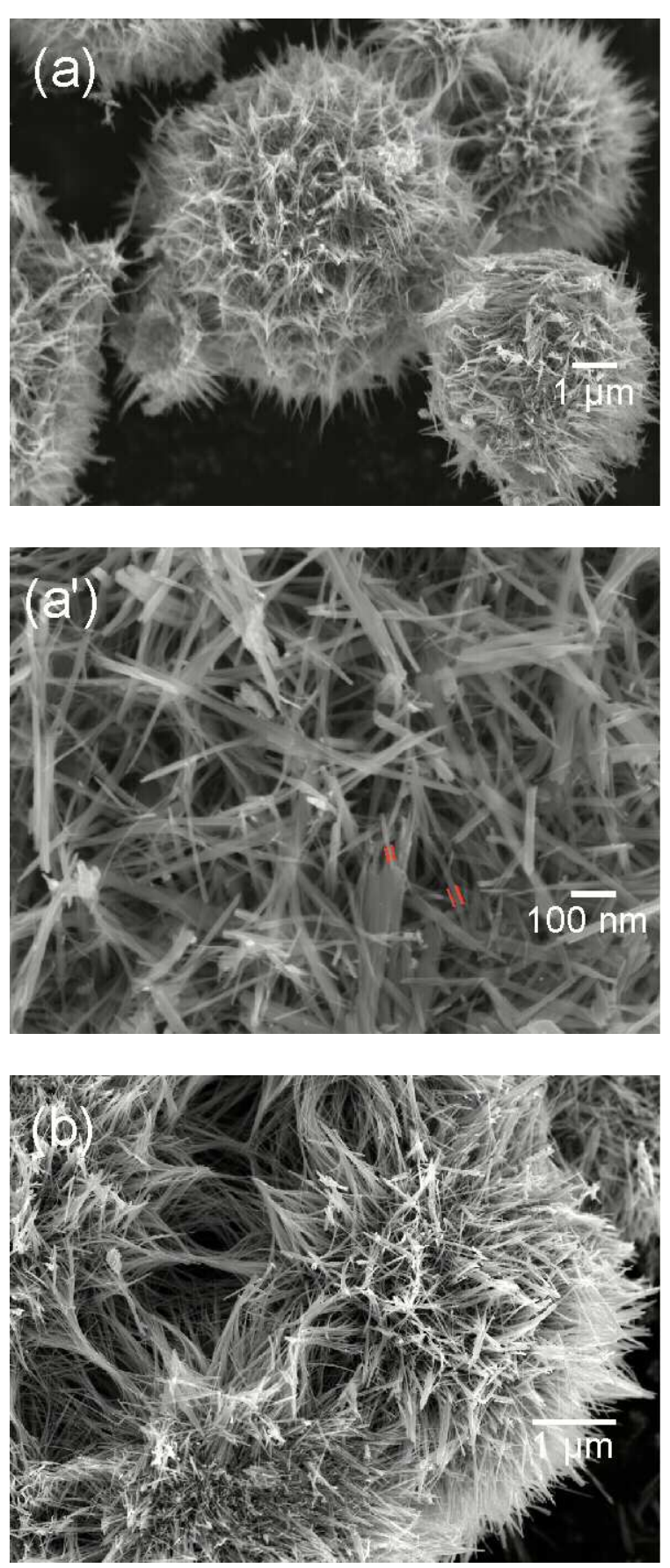

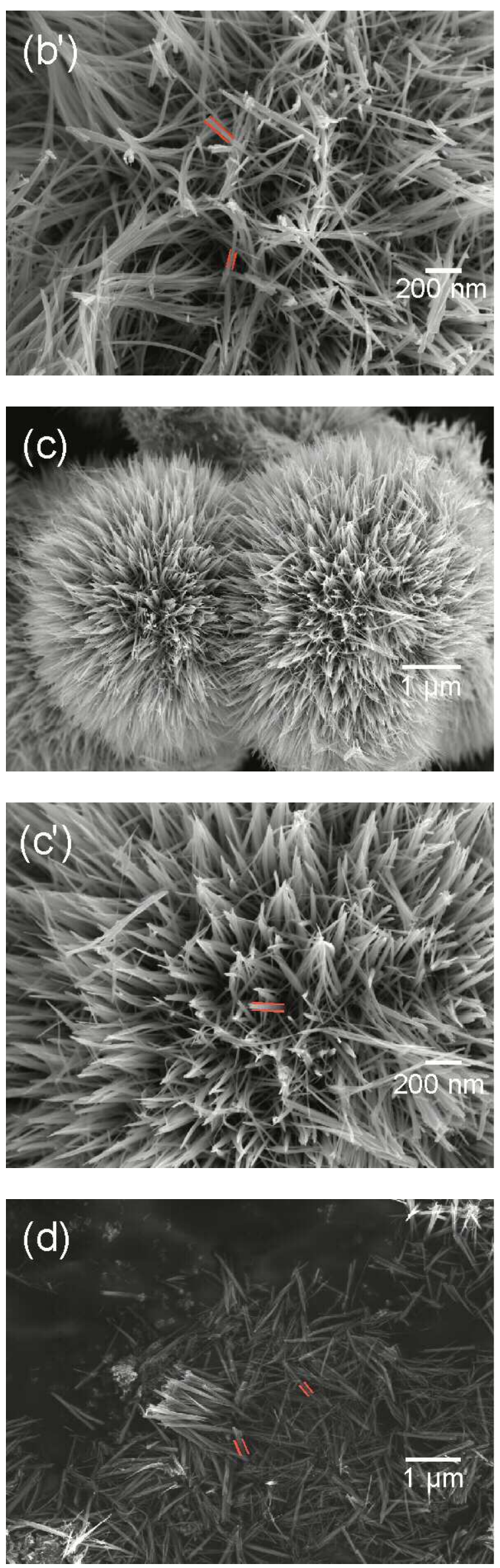
Figure 3
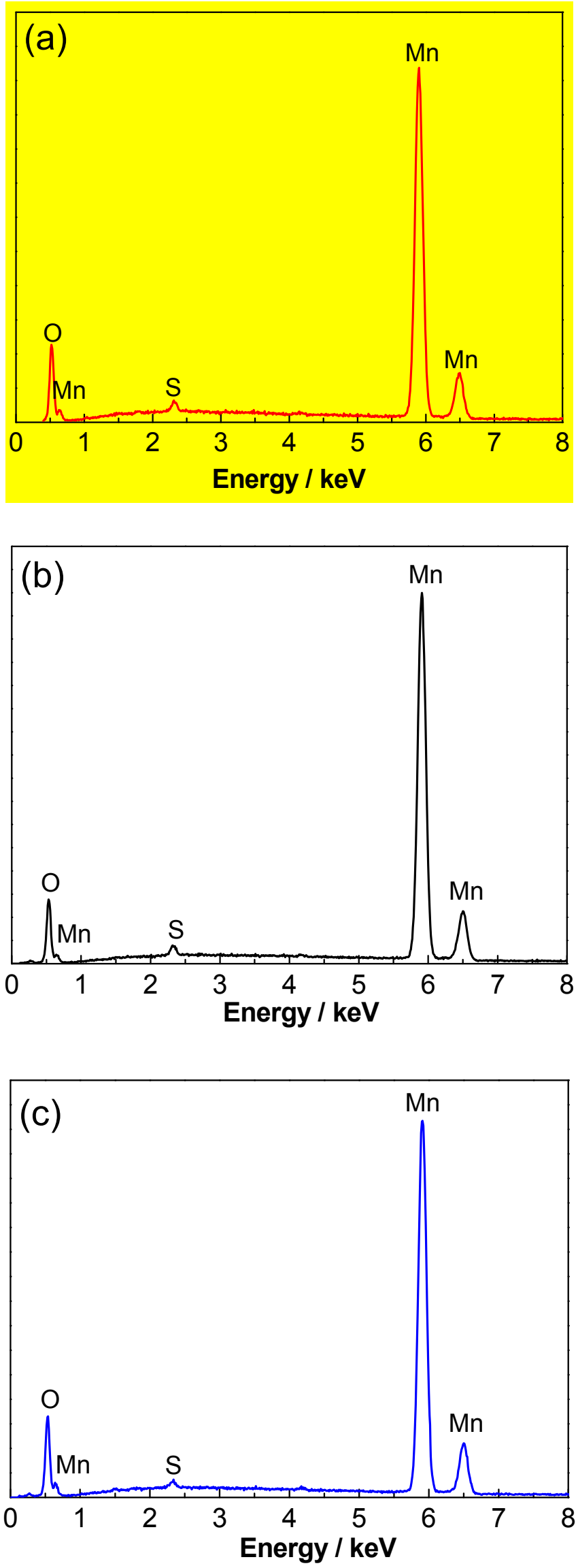
Figure 4
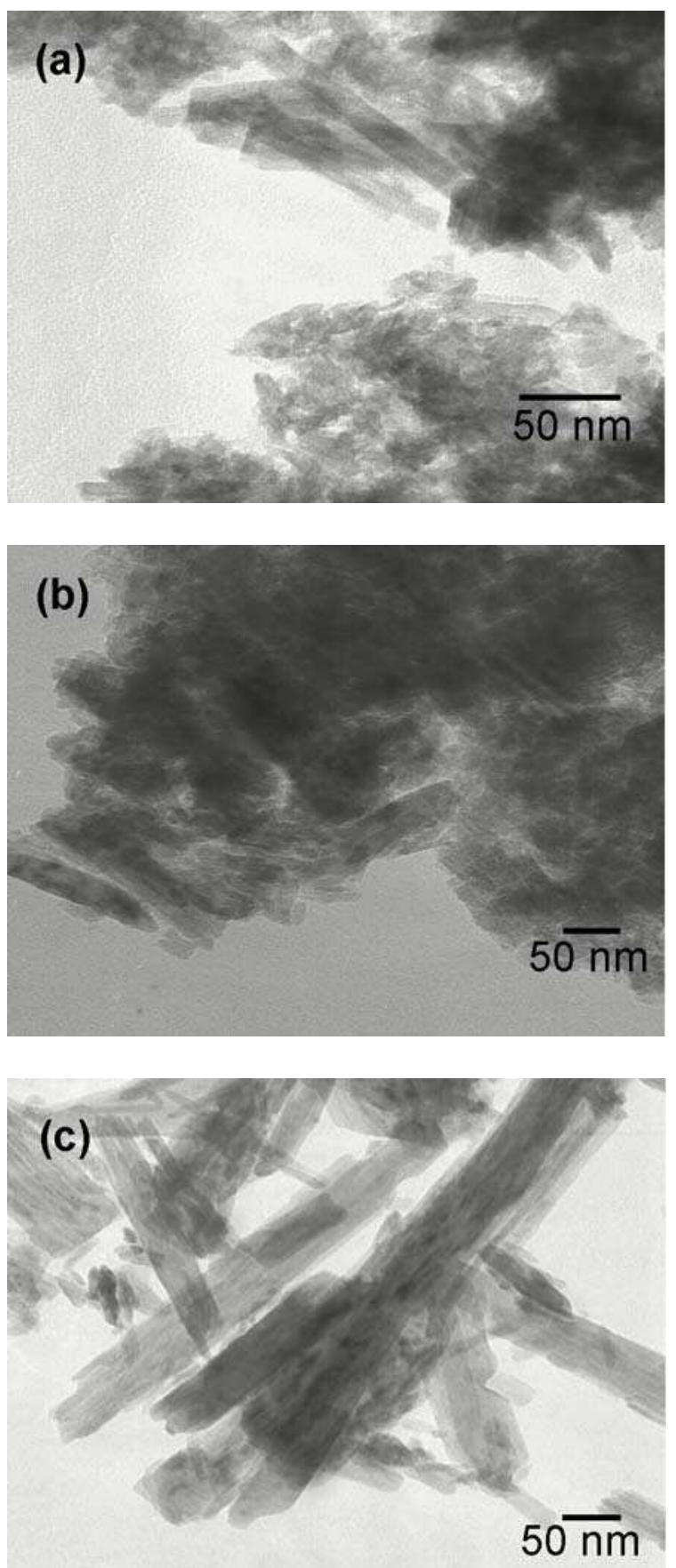
Figure 5
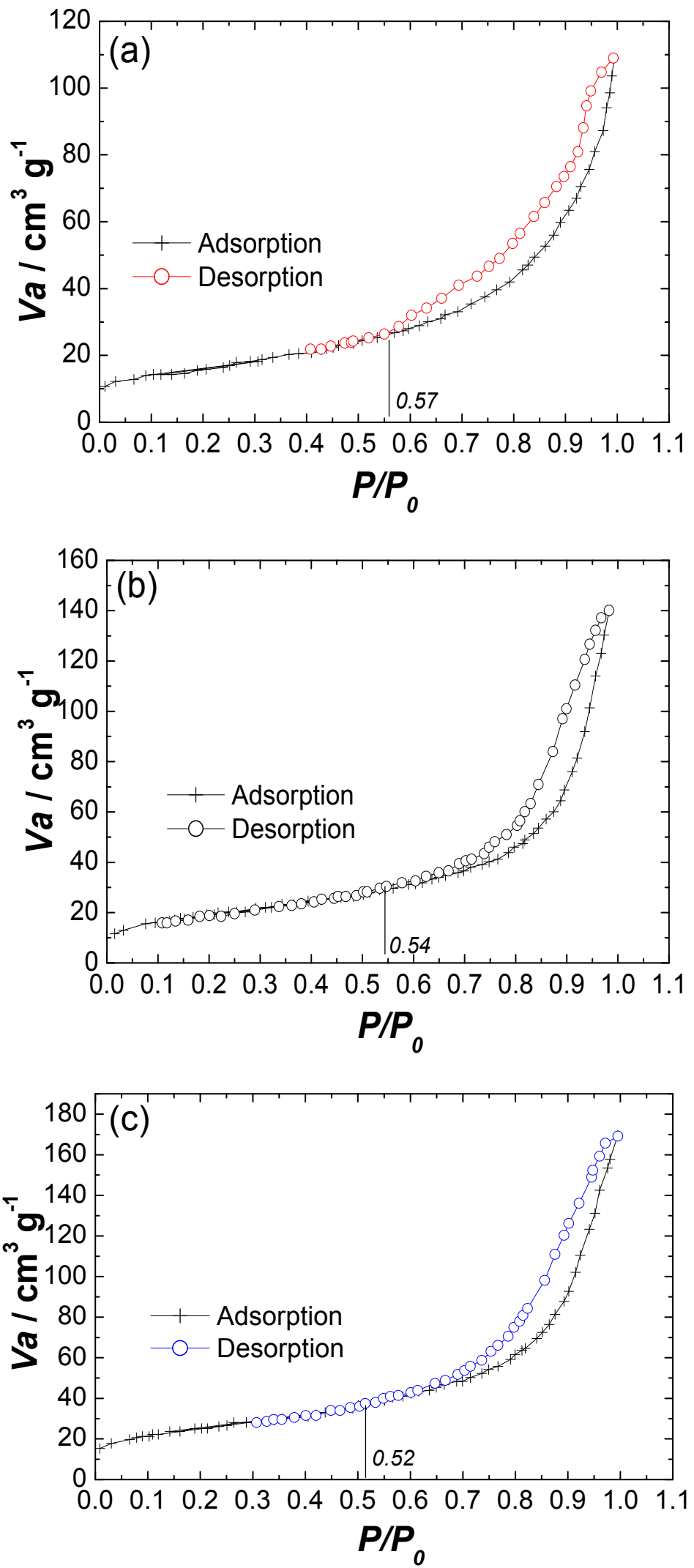
Figure 6

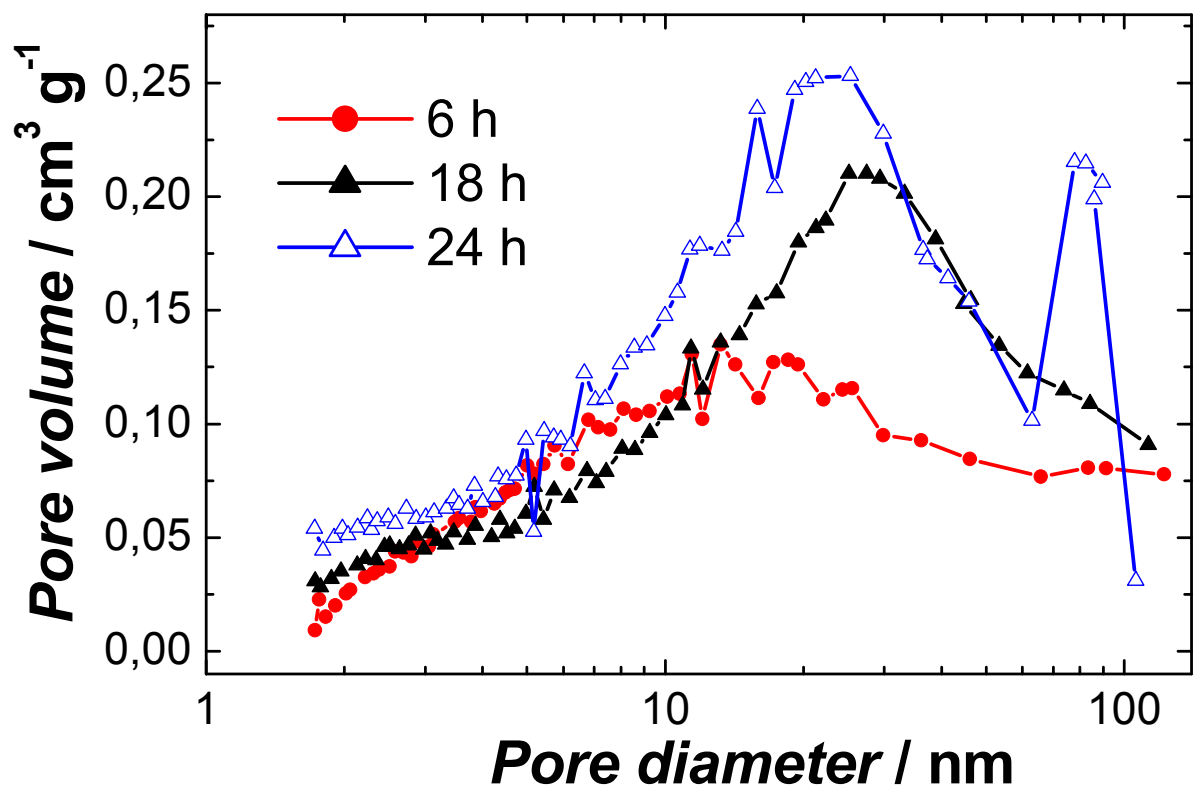


Figure 7

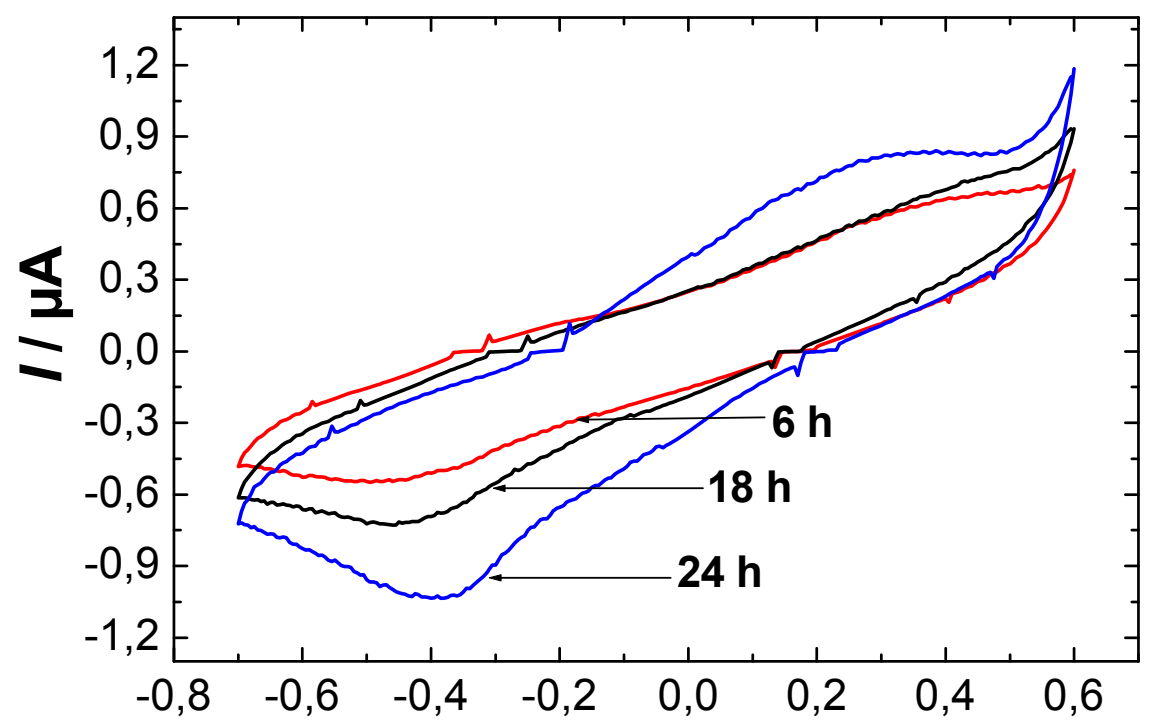

E I V vs. SCE 
Figure 8

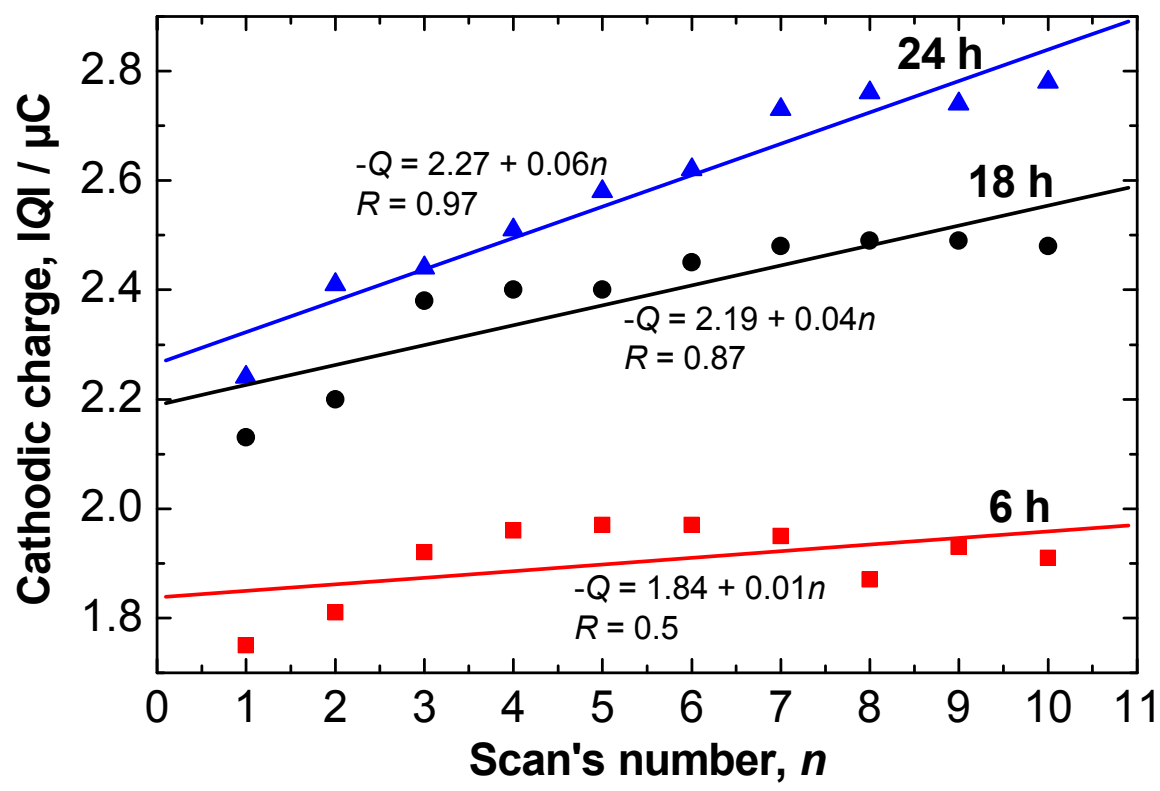

Figure 9

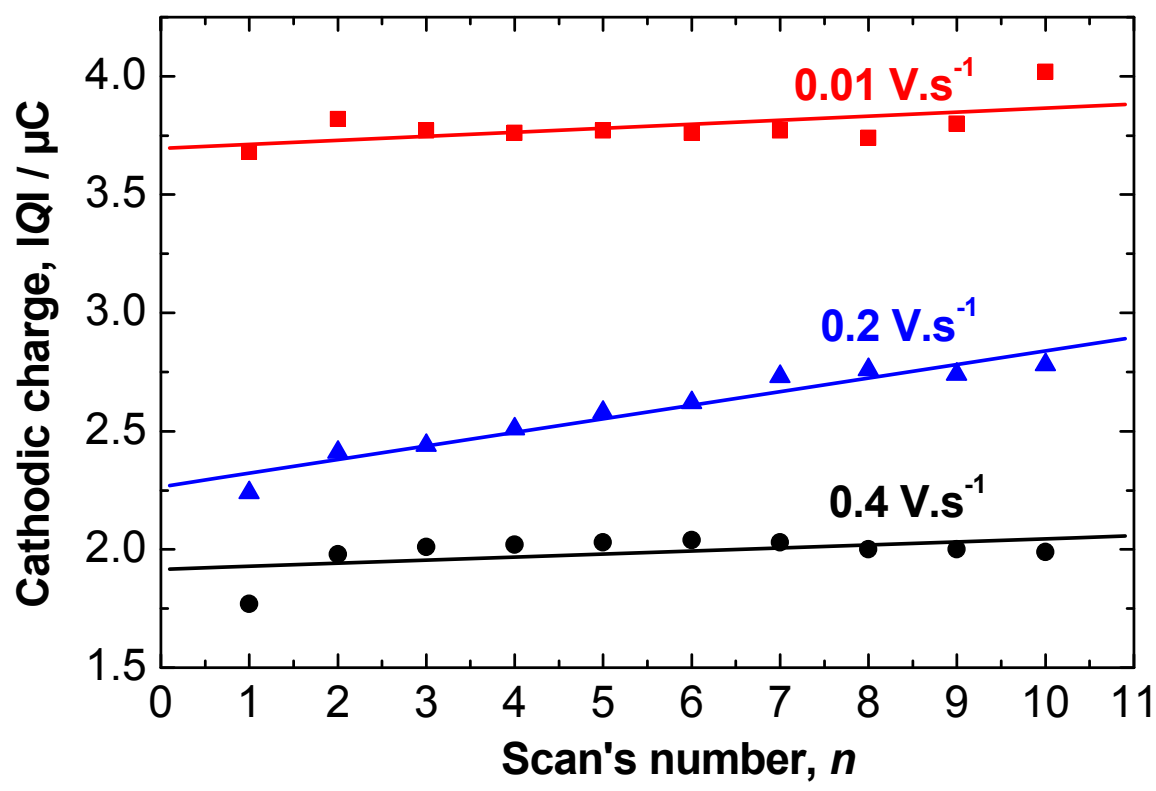


Figure 10

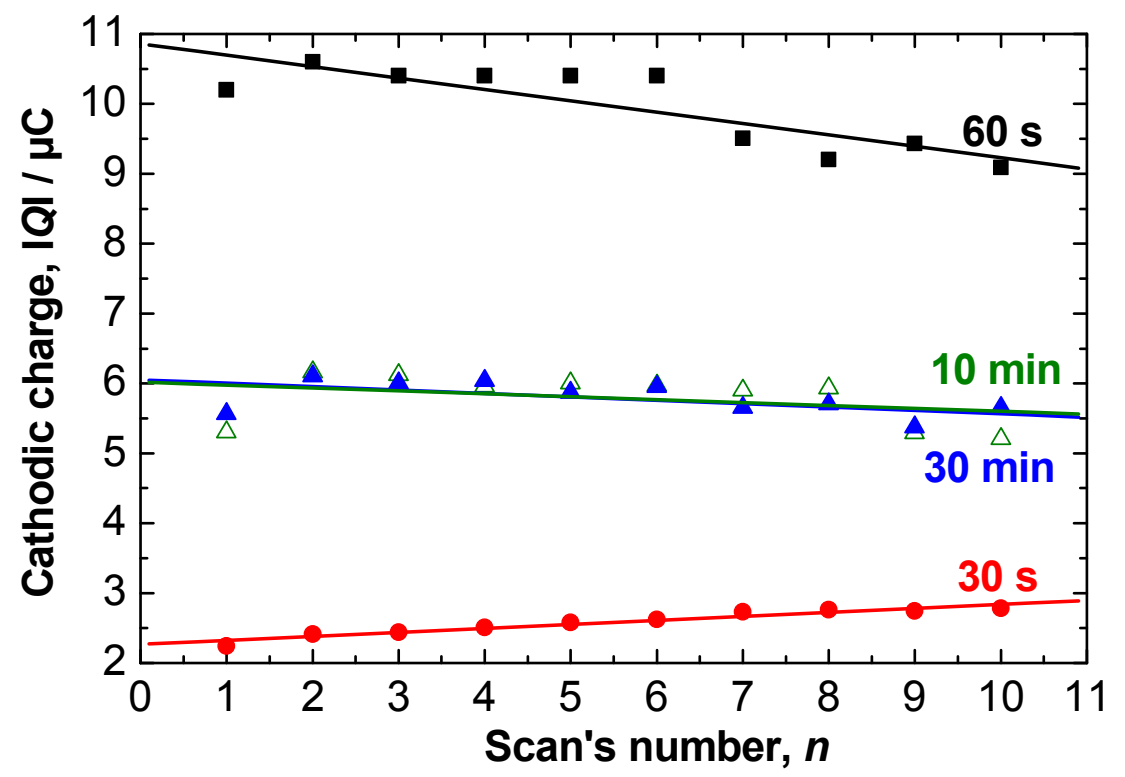


Figure 11

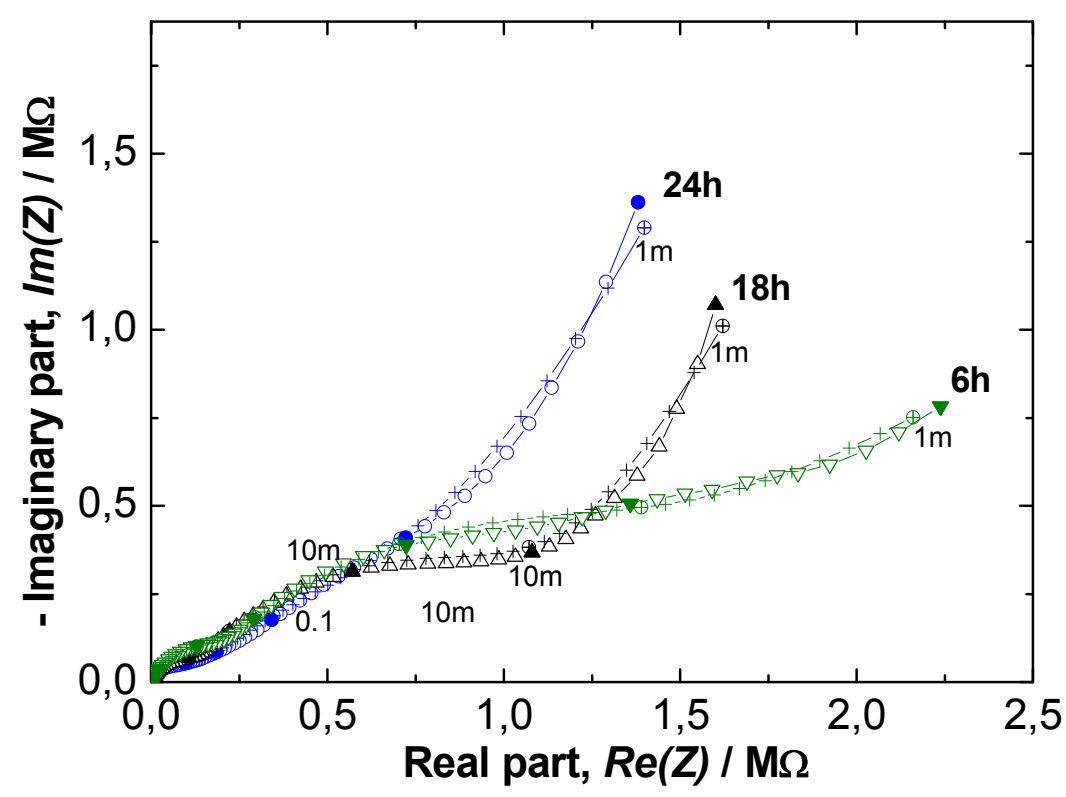


Figure 12

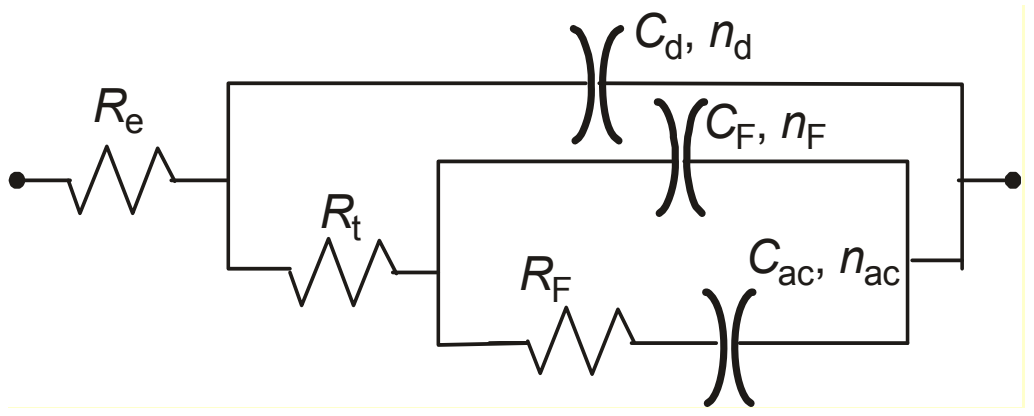


Figure 13

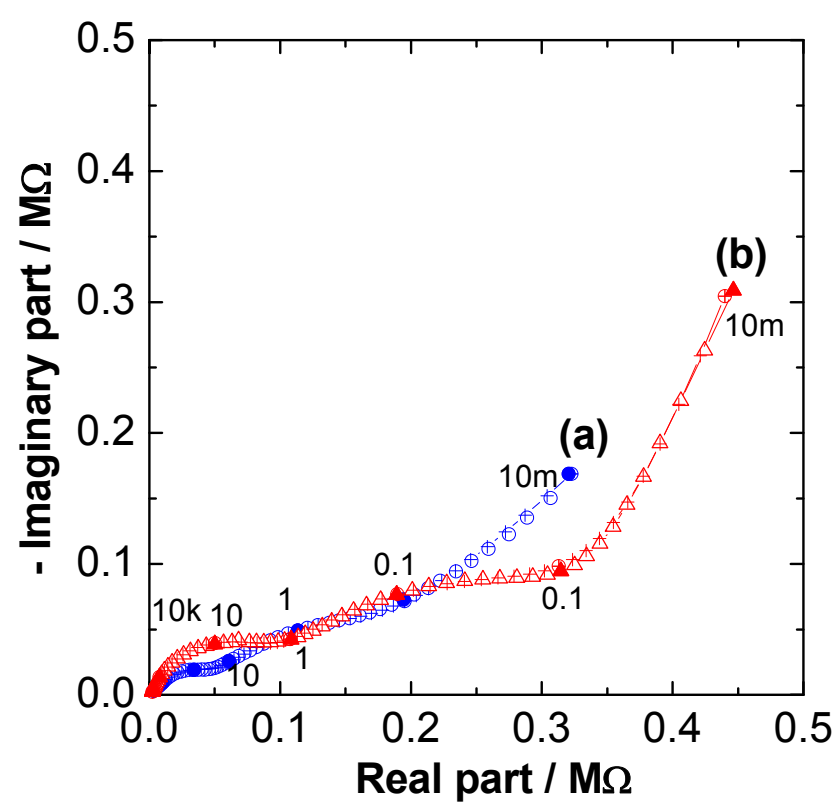




\section{Captions of Fig.s}

Fig. 1. XRD patterns of $\mathrm{MnO}_{2}$ powders synthesized at different durations. The (hkl) values corresponding to $\alpha-\mathrm{MnO}_{2}$ are given in a box.

Fig. 2. FEG-SEM images of (a), (b), (c), (d) Low and (a'), (b'), (c') high magnifications of $\mathrm{MnO}_{2}$ powders synthesized at different durations: (a) $6 \mathrm{~h}$, (b) $18 \mathrm{~h}$, (c) $24 \mathrm{~h}$ and (d) 8 days.

Fig. 3. EDX profiles of $\mathrm{MnO}_{2}$ powders synthesized at different durations: (a) $6 \mathrm{~h}$, (b) $18 \mathrm{~h}$, and (c) $24 \mathrm{~h}$.

Fig. 4. TEM images of $\mathrm{MnO}_{2}$ powders synthesized at different durations (General view): (a) 6 h, (b) $18 \mathrm{~h}$ and (c) $24 \mathrm{~h}$.

Fig. 5. Isotherms of $\mathrm{N}_{2}$ adsorption/desorption of the $\mathrm{MnO}_{2}$ powders synthesized at different durations: (a) $6 \mathrm{~h}$, (b) $18 \mathrm{~h}$ and (c) $24 \mathrm{~h}$.

Fig. 6. Comparison of the distribution of the pores size of $\mathrm{MnO}_{2}$ powders synthesized at different durations (calculated by BJH method).

Fig. 7. Polarization curves in $1 \mathrm{~mol} \mathrm{~L}^{-1} \mathrm{KOH}$ of $\mathrm{MnO}_{2}$ powders synthesized at different durations, potential scan rate $0.2 \mathrm{~V} \mathrm{~s}^{-1}$.

Fig. 8. Cathodic charge as function of scan number in $1 \mathrm{~mol} \mathrm{~L}^{-1} \mathrm{KOH}$ of the $\mathrm{MnO}_{2}$ powders synthesized at different durations. 
Fig. 9. Cathodic charge as function of scan rate in $1 \mathrm{~mol} \mathrm{~L}^{-1} \mathrm{KOH}$ of the $\mathrm{MnO}_{2}$ powder synthesized at $24 \mathrm{~h}$.

Fig. 10. Cathodic charge as function of immersion time in $1 \mathrm{~mol} \mathrm{~L}^{-1} \mathrm{KOH}$ of the $\mathrm{MnO}_{2}$ powder synthesized at $24 \mathrm{~h}$.

Fig. 11. Nyquist plots obtained in $1 \mathrm{~mol} \mathrm{~L}^{-1} \mathrm{KOH}$ of $\mathrm{MnO}_{2}$ powders synthesized at different durations and aged for 10 scans at $0.2 \mathrm{~V} \mathrm{~s}^{-1}$. Symbols: Experimental and "+" regressed data with the circuit illustrated in Fig. 12.

Fig. 12. Equivalent electrical circuit to represent the EIS diagrams.

Fig. 13. Nyquist plots in $1 \mathrm{~mol} \mathrm{~L}^{-1} \mathrm{KOH}$ of $\mathrm{MnO}_{2}$ powder synthesized at 24h: (a) assynthesized, (b) aged by 10 potential scans at $0.01 \mathrm{~V} \cdot \mathrm{s}^{-1}$. Symbols: circles and triangles, experimental; +, regressed data with the circuit illustrated in Figure 12.

\section{Caption of Table}

Table 1. Pore properties of the $\mathrm{MnO}_{2}$ powders synthesized by hydrothermal method at different durations. 